\title{
Gene polymorphisms and cytokine plasma levels as predictive factors of complications after cardiopulmonary bypass
}

Jérôme Jouan, MD, ${ }^{\mathrm{a}, \mathrm{c}}$ Lisa Golmard, PharmD,${ }^{\mathrm{b}, \mathrm{c}}$ Nadine Benhamouda, BASc, ${ }^{\mathrm{d}}$ Nicolas Durrleman, MD, ${ }^{\mathrm{a}}$
Jean-Louis Golmard, MD, PhD, ${ }^{\mathrm{e}}$ Raphaël Ceccaldi, PharmD,${ }^{\mathrm{b}}$ Ludovic Trinquart, ${ }^{\mathrm{f}}$ Jean-Noël Fabiani, MD,
PhD, ${ }^{\mathrm{a}, \mathrm{c}}$ Eric Tartour, MD, PhD, ${ }^{\mathrm{c}, \mathrm{d}}$ Xavier Jeunemaitre, MD, PhD, ${ }^{\mathrm{b}, \mathrm{c}, \mathrm{g}}$ and Philippe Menasché, MD, PhD ${ }^{\mathrm{a}, \mathrm{h}, \mathrm{h}}$

Objective: Cardiopulmonary bypass remains associated with significant morbidity and mortality, in part caused by a systemic inflammatory response that is unpredictable and variable among patients. Several limited studies have suggested associations of cytokine plasma levels or gene polymorphisms with outcome after cardiopulmonary bypass. The present study was to determine the relationships between several circulating cytokines and their polymorphisms (single nucleotide polymorphisms), and the occurrence of postoperative clinical events in patients who underwent coronary artery bypass grafting under cardiopulmonary bypass.

Methods: Patients were genotyped for single nucleotide polymorphisms of $L T A(\mathrm{Cys} 13 \mathrm{Arg},+252 \mathrm{~A}>\mathrm{G}), T N F$ $(-308 \mathrm{G}>\mathrm{A})$, IL6 $(-597 \mathrm{G}>\mathrm{A},-572 \mathrm{G}>\mathrm{C},-174 \mathrm{G}>\mathrm{C})$, IL10 $(-592 \mathrm{C}>\mathrm{A}, \mathrm{c} . * 117 \mathrm{C}>\mathrm{T})$, and APOE (Cys112Arg, Arg158Cys). Serum samples were collected preoperatively, immediately after cardiopulmonary bypass, and at different postoperative time points to measure cytokine serum levels by enzyme-linked immunosorbent assay. The clinical end point was the composite of postoperative death, low cardiac output syndrome, myocardial infarction, sepsis, and acute renal insufficiency.

Results: Single nucleotide polymorphisms IL6-572GC+CC/IL10-592CC were associated with the clinical end point $(P=.032$ and $P=.009$, respectively). In addition to preoperative clinical conditions, the other factor associated with the clinical end point was interleukin-10 plasma levels 24 hours after surgery $(P=.017)$. On the basis of these results, a predictive model of postoperative complications after coronary artery bypass grafting was created.

Conclusions: Our data suggest that focused genetic testing of the IL6-572G $>C$ and IL10-592C $>$ A single nucleotide polymorphisms might be a tool for identifying patients at the highest risk of poor tolerance to the inflammatory response to cardiopulmonary bypass and for implementing strategies to mitigate it, provided the generalization of these tests makes them reasonably affordable and thus favorably shifts their cost-to-benefit ratio. (J Thorac Cardiovasc Surg 2012;144:467-73)

\section{Supplemental material is available online.}

\footnotetext{
From the Departement de Chirurgie cardio-vasculaire, ${ }^{\text {a }}$ Assistance Publique-Hôpitaux de Paris, Hôpital Européen Georges Pompidou, Paris, France; Departement de Genetique, ${ }^{\text {b }}$ Assistance Publique-Hôpitaux de Paris, Hôpital Européen Georges Pompidou, Paris, France; Université Paris-Descartes, ${ }^{c}$ Sorbonne Paris Cité, Paris, France; Service d'Immunologie Biologique, ${ }^{\mathrm{d}}$ Assistance Publique-Hôpitaux de Paris, Hôpital Européen Georges Pompidou, Service d'Immunologie Biologique, Paris,

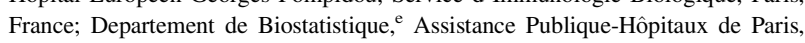
Groupe Hospitalier Pitié-Salpêtrière, Paris, France; United'Epidemiologie et de Recherche Clinique, ${ }^{\mathrm{f}}$ Assistance Publique-Hôpitaux de Paris, Hôpital Européen Georges Pompidou, Paris, France; INSERM UMR-S970, ${ }^{\mathrm{g}}$ PARCC, Centre de recherche HEGP, Paris, France; and INSERM UMR 633, ${ }^{\mathrm{h}}$ Hôpital Européen Georges Pompidou, Paris, France.

J.J. and L.G. contributed equally to this article.

This study was funded by INSERM and the Programme Hospitalier de Recherche Clinique (PHRC P030405)

Disclosures: Authors have nothing to disclose with regard to commercial support.

Received for publication Aug 22, 2011; revisions received Oct 26, 2011; accepted for publication Dec 14, 2011; available ahead of print Jan 20, 2012.

Address for reprints: Jérôme Jouan, MD, Département de Chirurgie cardiovasculaire, Hôpital Européen Georges Pompidou, 20, rue Leblanc, 75015 Paris (E-mail: jouanjerome@ hotmail.com).

$0022-5223 / \$ 36.00$

Copyright $(92012$ by The American Association for Thoracic Surgery doi:10.1016/j.jtcvs.2011.12.022
}

Despite many improvements over these last decades, cardiopulmonary bypass (CPB) still induces an acute inflammatory response associated with significant morbidity and mortality. ${ }^{1}$ Disruption in the balance between pro- and anti-inflammatory cytokine levels has been suggested to be a key factor of a systemic inflammatory response syndrome (SIRS), resulting in organ dysfunction affecting the heart, brain, lungs, and kidneys. However, the intensity of this inflammatory response is variable among patients and remains unpredictable.

Unpredictability of the inflammatory response may be explained by genetic variability. Most studied polymorphisms are single nucleotide polymorphisms (SNPs). An SNP is a genetic variation that occurs when a nucleotide replaces another one, present in more than $1 \%$ of the population. Most commonly, these variations are found in the DNA between genes. When SNPs occur within a gene or in a regulatory region near a gene, they may play a role in disease by affecting the gene function. SNPs located in gene promoters can result in an upregulation or downregulation of the gene expression and then an increase or decrease of the protein level. Coding SNPs, which lead to an amino acid substitution, can affect the protein function. 


$$
\begin{aligned}
& \text { Abbreviations and Acronyms } \\
& \text { ARI = acute renal insufficiency } \\
& \text { CABG }=\text { coronary artery bypass grafting } \\
& \text { CE }=\text { clinical end point } \\
& \text { COPD }=\text { chronic obstructive pulmonary disease } \\
& \text { CPB }=\text { cardiopulmonary bypass } \\
& \text { IL }=\text { interleukin } \\
& \text { ITA }=\text { internal thoracic artery } \\
& \text { LCOS }=\text { low cardiac output syndrome } \\
& \text { LVEF }=\text { left ventricular ejection fraction } \\
& \text { MI }=\text { myocardial infarction } \\
& \text { SIRS }=\text { systemic inflammatory response } \\
& \text { SNP }=\text { syndrome } \\
& \text { TNF }=\text { tumor nucleotide polymorphism }
\end{aligned}
$$

Several studies have shown associations between cytokine plasma levels or gene polymorphisms and clinical outcome after CPB, but these studies often focused on a single cytokine ${ }^{2-5}$ or one clinical complication. ${ }^{6}$ In an attempt to overcome these limitations, we carried out a prospective study on a cohort of patients undergoing coronary artery bypass grafting $(\mathrm{CABG})$ under $\mathrm{CPB}$ and evaluated the impact of gene polymorphisms encoding proinflammatory (interleukin [IL]-6 and tumor necrosis factor $[\mathrm{TNF}]-\alpha$ ) and anti-inflammatory (IL10) cytokines, as well as the corresponding plasma levels, on postoperative complications. The overall objective was to assess whether a focused genetic screening could help identify patients at high risk of developing post-CABG inflammatory complications.

\section{MATERIALS AND METHODS \\ Patient Population}

A single-center prospective study was carried out in a cohort of 126 patients undergoing CABG under CPB. This study was approved by our local ethics committee. All patients provided informed consent. All patients aged more than 20 years, referred for $\mathrm{CABG}$ under $\mathrm{CPB}$ and cardiac arrest, were included. Exclusion criteria were age greater than 80 years, emergency surgery, associated surgical procedures, left ventricular ejection fraction (LVEF) less than 30\%, nonsteroidal anti-inflammatory drug or corticosteroid use, preoperative dialysis, redo-surgery, single-vessel disease, hepatic insufficiency, and current infection. Chronic renal insufficiency and preoperative symptomatic cardiac insufficiency, defined by the association of LVEF less than 50\% and dyspnea New York Heart Association class III/IV or recent hospitalization requirement for pulmonary edema, were not exclusion criteria.

\section{Surgical Procedure}

Patients were operated via a midline sternotomy, and CPB was performed under normothermia between $34^{\circ} \mathrm{C}$ and $37^{\circ} \mathrm{C}$. Cardiac arrest was obtained by normothermic, intermittent antegrade or continuous retrograde, whole blood cardioplegia. All patients underwent the implantation of an internal thoracic artery (ITA) on the left descending coronary artery.
Additional bypasses were done with the use of ITA, radial artery, or saphenous vein conduits.

\section{Definitions of the Clinical End Point}

The clinical end point (CE) included postoperative death from any cause, myocardial infarction (MI), low cardiac output syndrome (LCOS), stroke, acute renal insufficiency (ARI), or sepsis. Death was reported if it occurred within 30 days or at any time during hospital admission. MI was defined as typical electrical changes on postoperative electrocardiogram or abnormal changes in wall motion on echocardiography and postoperative cardiac troponin I plasma levels greater than $15 \mu \mathrm{g} / \mathrm{L}$ at any time after surgery. LCOS was defined by the requirement for mechanical assistance or prolonged inotropic support (epinephrine or dobutamine $>5 \mu \mathrm{g}$ / $\mathrm{kg} / \mathrm{min}$ for $>30$ minutes in the intensive care unit) to maintain systolic blood pressure greater than $90 \mathrm{~mm} \mathrm{Hg}$ or cardiac index greater than 2.2 $\mathrm{L} / \mathrm{m}^{2}$. Stroke was reported if any clinical suspicion of cerebral ischemic symptoms lasting more than 24 hours was confirmed by computed tomography. Acute renal insufficiency was defined as plasma creatinine levels greater than $200 \mu \mathrm{mol} / \mathrm{L}$ or, particularly for patients having a baseline plasma creatinine level greater than $150 \mu \mathrm{mol} / \mathrm{L}$, the requirement for hemodialysis at any time after surgery. Sepsis encompassed several components (pneumonia, pyelonephritis, mediastinitis, or superficial wound infection).

\section{Cytokine Measurements}

IL10 and IL6 plasma levels were measured by ELISA (Diaclone, Besançon, France). An ultrasensitive TNF $\alpha$ ELISA (R\&D Systems, Lille, France) was used for TNF $\alpha$ measurement as previously described. ${ }^{7}$ Assays were performed at 3 time points: before anesthesia, at the end of CPB (IL10) or 4 hours thereafter (IL6 and TNF $\alpha$ ), and 24 hours after CPB. The end-CPB and 4-hour post-CPB study points were selected on the basis of previous studies showing that they correspond to peak levels for IL10 or IL6 and TNF $\alpha$, respectively. ${ }^{7,8}$

\section{Selection of Candidate Genes and Polymorphisms}

Five candidate genes involved in the pathogenesis of inflammation were selected on the basis of pathway analysis and a review of association studies reported in the literature., ${ }^{2,3-11}$ The objective was not to capture a high proportion of genetic information at each locus, but rather to concentrate on SNPs previously associated with the trait, with an emphasis on their minor allele frequency ( $\geq 5 \%$ except for one), or those previously shown to be functional. $^{4,12-14}$ The 10 selected SNPs were IL10-592C $>$ A, c. $* 117 \mathrm{C}>\mathrm{T}$, IL6$597 \mathrm{G}>\mathrm{A},-572 \mathrm{G}>\mathrm{C},-174 \mathrm{G}>\mathrm{C}, T N F-308 \mathrm{G}>\mathrm{A}, L T A+252 \mathrm{~A}>\mathrm{G}, \mathrm{Cys} 13 \mathrm{Arg}$, and the 2 polymorphisms determining $\varepsilon 2,3$, and 4 alleles of the $A P O E$ gene (Table E1). This limited number of SNPs also had the advantage of not weakening the power of the statistical analysis by testing many associations.

\section{Genomic DNA Isolation and Genotype Analysis}

Genomic DNA was isolated from peripheral blood leukocytes, collected preoperatively from blood samples, by proteinase $\mathrm{K}$ digestion and saline extraction. $T N F-308 \mathrm{G}>\mathrm{A}$ and $L T A+252 \mathrm{~A}>\mathrm{G}$ were genotyped by polymerase chain reaction-restriction fragment length polymorphism with $\mathrm{NcoI}$ restriction enzyme (Promega Corp, Madison, Wis) according to the manufacturer's instructions. Other SNPs were genotyped by direct sequencing using kits and run on a 3730 DNA analyzer (Applied Biosystems, Carlsbad, Calif), and DNA sequences were analyzed by the Sequencher software (Gene Codes Corporation, Ann Arbor, Mich) (Table E2). Genotype distribution did not differ significantly from that predicted by the Hardy-Weinberg equilibrium law for each polymorphism.

\section{Statistical Analysis}

Descriptive statistics used means and standard deviations for quantitative variables and numbers and percentages for qualitative variables. HardyWeinberg equilibrium of genotypes was tested using chi-square tests. 
The statistical analysis was performed using 2 steps. In the first step, a univariate analysis aimed at assessing risk factors of $\mathrm{CE}$ was performed. This analysis embedded a genotype-phenotype association study. Genotypes were coded as qualitative variables, with 3 or 2 modalities, assuming a dominant effect. The univariate analysis was based on 2-sample Wilcoxon tests for quantitative data and chi-square or Fisher exact tests, when chi-square tests were not valid, for qualitative data. A Bonferroni correction was applied for genotypes.

In the second step, variables associated with $\mathrm{CE}$ in the univariate analysis with a $P$ value less than .20 were included in a stepwise logistic regression to build a predictive model of complications. Variables retained in the final model had a $P$ value less than .05 using the Wald test and were used for building a predictive score. A score threshold was determined arbitrarily to define a high-risk group. Evaluation of the predictive power of the model was based on the area under the receiver operating characteristic curve, sensitivity, specificity, positive and negative predictive values, and relative risk of complications between the high-risk and low-risk groups. These parameters, a part area under the receiver operating characteristic curve, were first computed on the sample, and in a second step their means and $95 \%$ confidence intervals were estimated by nonparametric Bootstrap, involving 10,000 Bootstrap samples. Confidence intervals were determined using 2.5 and 97.5 percentiles of the Bootstrap sample distribution.

Relationships between cytokine log-concentrations and covariates were tested, in a univariate step, using 2-sample Wilcoxon tests for binary covariates, nonparametric analyses of variance (Kruskal-Wallis tests) for other qualitative covariates, including genotypes, and Spearman-rank correlation coefficient tests for quantitative covariates. The corresponding multivariable analyses were performed using mixed linear models with a logtransformation of the data to normalize the residuals and fit the model assumptions. The cytokine kinetics ( 3 log-concentrations by subject) were analyzed using mixed linear models, with log-concentrations considered as repeated data. All tests were 2-sided. Computations were performed using the SAS v9 statistical package (SAS Institute Inc, Cary, NC).

\section{RESULTS}

\section{Clinical Events}

Patient characteristics are summarized in Table 1. Procedures included 2, 3, or 4 CABGs in 35 patients $(28 \%), 73$ patients $(58 \%)$, and 18 patients (14\%), respectively. Revascularization was exclusively done with the 2 ITAs in 26 patients $(21 \%)$. Intrathoracic arterial balloon pump or inotropic support was required for weaning from CPB in 2 patients $(2 \%)$ and 16 patients $(13 \%)$, respectively. Perioperative red blood cell transfusions were needed in 45 patients $(36 \%)$. Mean intensive care unit length of stay was $2.2 \pm 3.9$ days, and mean duration under mechanical ventilation was $19.9 \pm 63.9$ hours.

Of the 126 patients, $18(14.3 \%)$ experienced any one of the clinical complications included in CE. Complications included were 4 deaths $(3.2 \%), 7$ MIs $(5.6 \%), 11$ cases of LCOS $(8.7 \%), 8$ cases of ARI $(6.3 \%)$, and 10 cases of sepsis $(7.9 \%)$. There was no stroke. Clinical conditions associated with CE were chronic obstructive pulmonary disease (COPD) $(P=.054)$, preoperative symptomatic cardiac insufficiency $\left(P=7.10^{-4}\right)$, and LVEF less than $50 \%(P=.041)$ (Table 2$)$.

\section{Cytokine Circulating Levels and Their Association With Genetic Polymorphisms}

Plasma levels of IL10, IL6, and TNF $\alpha$ were elevated at the end of CPB (IL10) or 4 hours thereafter (IL6 and
TABLE 1. Preoperative and perioperative patient characteristics

\begin{tabular}{|c|c|c|c|}
\hline & $\mathbf{C E}$ & No CE & $\boldsymbol{P}$ \\
\hline n $(\%)$ & $18(14)$ & $108(86)$ & \\
\hline \multicolumn{4}{|l|}{ Preoperative characteristics } \\
\hline Age & $67.3 \pm 9.5$ & $63.4 \pm 9.0$ & .11 \\
\hline Gender M/F ( $\%$ male $)$ & $16 / 2(89)$ & $95 / 13(88)$ & NS \\
\hline BMI & $25.7 \pm 3.6$ & $27.0 \pm 3.7$ & NS \\
\hline \multicolumn{4}{|l|}{ Cardiovascular risk factors } \\
\hline Diabetes mellitus & $4(22)$ & $31(29)$ & NS \\
\hline Hypertension & $13(72)$ & $69(64)$ & NS \\
\hline Hypercholesterolemia & $15(83)$ & $88(81)$ & NS \\
\hline Tobacco consumption & $4(22)$ & $29(27)$ & NS \\
\hline COPD & $5(28)$ & $11(10)$ & .06 \\
\hline Previous MI & $8(44)$ & $39(36)$ & NS \\
\hline Preoperative symptomatic & $5(28)$ & $2(2)$ & $7.10^{-4}$ \\
\hline \multicolumn{4}{|l|}{ Cardiac insufficiency } \\
\hline Treated atrial fibrillation & $2(11)$ & $4(4)$ & NS \\
\hline LVEF $30 \%-50 \%$ & $5(28)$ & $10(9)$ & .05 \\
\hline \multicolumn{4}{|l|}{ Intraoperative characteristics } \\
\hline Operative duration (h) & $4.2 \pm 0.8$ & $4.0 \pm 0.8$ & NS \\
\hline CPB duration (h) & $1.6 \pm 0.4$ & $1.5 \pm 0.5$ & NS \\
\hline Aortic clamp duration (h) & $0.9 \pm 0.4$ & $0.9 \pm 0.3$ & NS \\
\hline $\begin{array}{l}\text { Lowest temperature under } \\
\mathrm{CPB}\left({ }^{\circ} \mathrm{C}\right)\end{array}$ & $35.1 \pm 0.6$ & $35.1 \pm 0.9$ & NS \\
\hline
\end{tabular}

$B M I$, Body mass index; $N S$, not significant.

$\mathrm{TNF} \alpha)$ and decreased 24 hours after $\mathrm{CPB}\left(P<10^{-4}\right)$ (Figure 1). Cytokine plasma levels 24 hours after CPB remained higher (IL6, $P<10^{-4}$ ) or were not significantly higher (IL10 and TNF $\alpha$ ) than baseline levels. IL10 plasma levels 24 hours after CPB were found to be significantly associated with $\mathrm{CE}(P=.017)$ (Figure 2, Table 2).

TABLE 2. Risk factors for clinical complications according to clinical end point

\begin{tabular}{|c|c|c|c|}
\hline & $\begin{array}{c}\text { CE n }(\%) \\
\text { or median } \\
(\text { Q1-Q3) }\end{array}$ & $\begin{array}{c}\text { No CE n }(\%) \\
\text { or median } \\
(Q 1-Q 3)\end{array}$ & $\begin{array}{c}\text { Univariate } \\
P(\text { Bonferroni } P)\end{array}$ \\
\hline Age (/10) & $6.80(6.10-7.60)$ & $6.30(5.65-7.00)$ & .106 \\
\hline COPD & $5(27.8)$ & $11(10.2)$ & .054 \\
\hline $\begin{array}{l}\text { Preoperative } \\
\text { symptomatic } \\
\text { cardiac } \\
\text { insufficiency }\end{array}$ & $5(27.8)$ & $2(1.9)$ & $7.10^{-4}$ \\
\hline LVEF $30 \%-50 \%$ & $5(27.8)$ & $10(9.3)$ & .041 \\
\hline \multicolumn{4}{|l|}{ IL6-572G $>\mathrm{C}^{*}$} \\
\hline GG & $12(66.7)$ & $96(88.9)$ & .032 \\
\hline GC & $6(33.3)$ & $10(9.3)$ & $(.32)$ \\
\hline $\mathrm{CC}$ & $0(0.0)$ & $2(1.9)$ & \\
\hline \multicolumn{4}{|l|}{ IL10-592C $>\mathrm{A}^{*}$} \\
\hline $\mathrm{CC}$ & $16(88.9)$ & $54(50.0)$ & .009 \\
\hline $\mathrm{CA}$ & $2(11.1)$ & $44(40.7)$ & (.09) \\
\hline AA & $0(0.0)$ & $10(9.3)$ & \\
\hline $\begin{array}{l}\text { 24-h IL10 } \\
\text { concentration }\end{array}$ & $11.0(2.0-37.0)$ & $2.0(0.0-9.0)$ & .017 \\
\hline
\end{tabular}

IL $10-592 \mathrm{C}>\mathrm{A}$ is coded $(\mathrm{CC}=1, \mathrm{CA}$ or $\mathrm{AA}=0)$. 


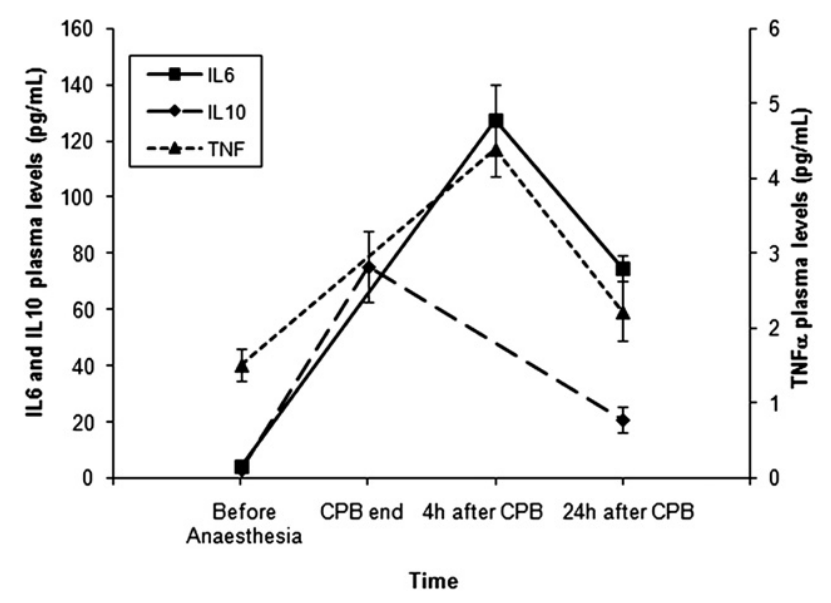

FIGURE 1. Perioperative cytokine plasma levels. $C P B$, Cardiopulmonary bypass; $I L$, interleukin; $T N F$, tumor necrosis factor.

When cytokine plasma levels were assessed in relation with gene polymorphisms (Table E3), IL10 plasma levels 24 hours after $\mathrm{CPB}$ were found to be associated with SNP IL6-572G $>$ C ; patients with IL6-572CC genotype had the highest IL10 levels $(P=.040)$. IL6 plasma levels 24 hours after CPB were associated with $A P O E$ polymorphism; patients with $A P O E 3 / 3$ genotype had lower IL6 levels than those with $A P O E 3 / 4$ or $3 / 2$ genotypes $(P=.011$ and $P=.027$ in univariate and multivariable analyses, respectively). A weak association was observed between $\mathrm{TNF} \alpha$ plasma levels before anesthesia and SNP TNF-308G $>\mathrm{A}$; patients with $T N F-308 \mathrm{AA}$ genotype had the lowest TNF $\alpha$ levels $(P=.073$ and $P=.039$ in univariate and multivariable analyses, respectively). When analyzed over the 24hour kinetics, TNF $\alpha$ plasma levels were associated with SNP LTA Cys13Arg $(P=.019)$; patients with LTA 13ArgArg genotype had the highest TNF $\alpha$ plasma levels before

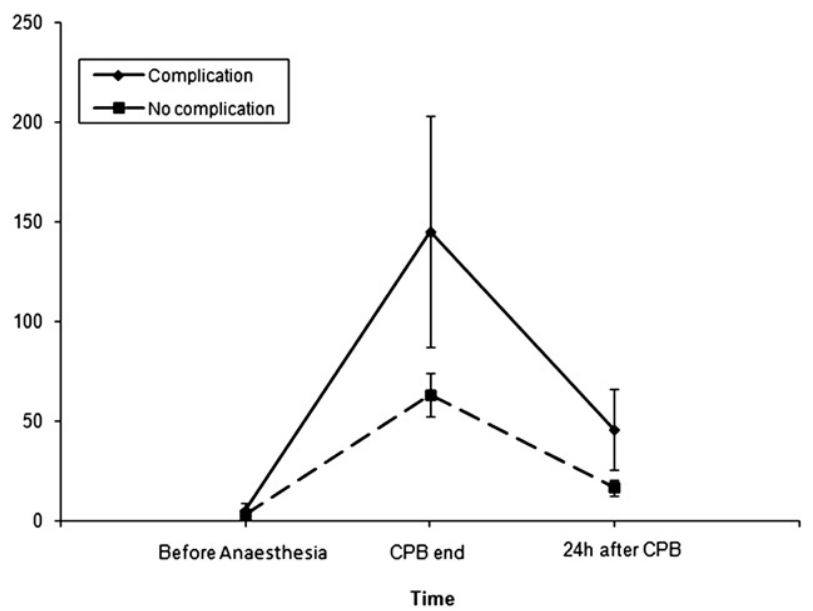

FIGURE 2. Perioperative IL10 plasma levels and the occurrence of clinical complications according to the CE. Error bars represent the standard error of the mean. $C P B$, Cardiopulmonary bypass.

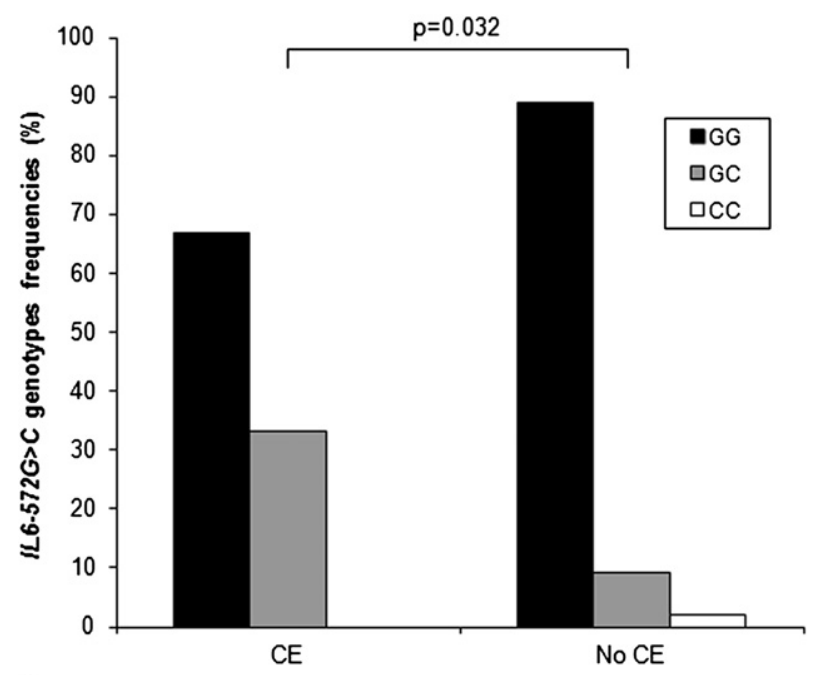

A

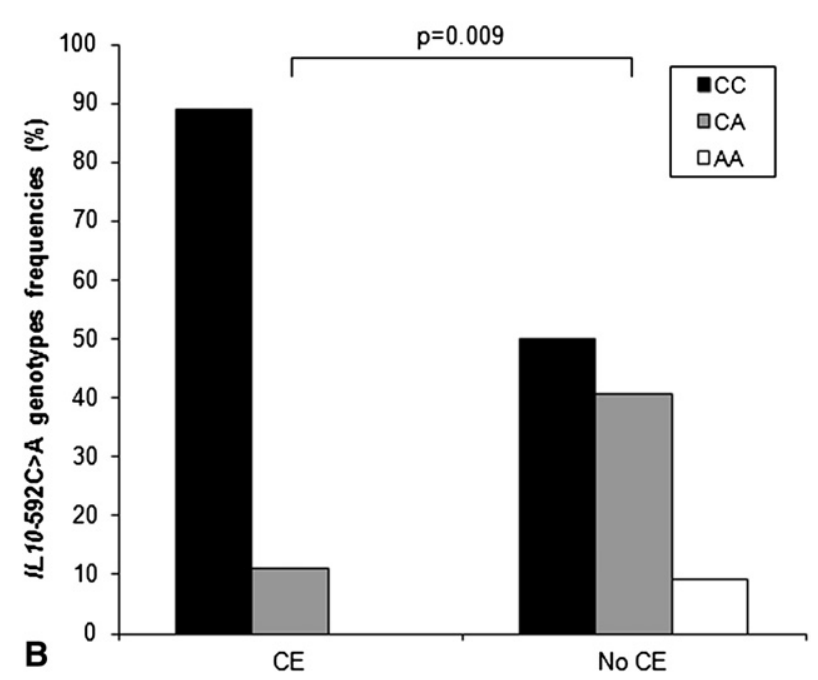

FIGURE 3. Relations between SNPs and CE. A, SNP IL6-572G $>$ C. B, SNP IL10-592C > A. CE, Clinical end point.

anesthesia and 24 hours after CPB, but TNF $\alpha$ levels 4 hours after CPB were similar for the 3 genotypes.

\section{Genetic Polymorphisms and Postoperative Adverse Events}

Genetic polymorphisms associated with CE were SNPs IL6-572G $>\mathrm{C}$ and IL10-592C $>\mathrm{A}$, because a higher number of complications included in this end point was seen in patients with IL6-572GC or CC genotypes (OR, 8.5; $P=.004$ ) or the IL10-592CC genotype (OR, 11.4; $P=.009$ ). However, these observations were not supported after Bonferroni correction (Figure 3, $A$ and $B$, Table 2).

\section{Predictive Model}

We defined a prediction score for patients at high risk of complications. The predictive score formula was 
score $=-7.2+0.69 \times($ age $/ 10)-2.1 \times($ IL6-572GG $)+$ $2.4 \times($ IL 10-592CC $)+2 \times($ COPD $)+4.3 \times($ treated cardiac insufficiency).

A score greater than -0.65 had a $68 \%$ predictive positive value, a $95 \%$ predictive negative value, a $72 \%$ sensitivity, a $94 \%$ specificity, and a relative risk of 14.64 . These predictive parameters were estimated by bootstrap $(n=10,000)$. Bootstrap parameters had a mean and 95\% confidence interval of 68 (45-88), 95 (91-99), 71 (48-92), 94 (89-98), and 20.71 (5.73-96.25), respectively.

\section{DISCUSSION}

The CPB-induced SIRS has been widely studied for many years. It has now been convincingly demonstrated that this SIRS involves at least 3 interconnected plasma protease pathways: the complement cascade, cellular responses, and cytokine secretion. ${ }^{8}$ More recently, several studies have shown conflicting results concerning the influence of genetic polymorphisms on cytokine release and the related magnitude of this inflammatory response. ${ }^{2,15} \mathrm{By}$ using a relatively large group of patients who underwent CABG, a strict standardized procedure, and definition of the $\mathrm{CE}$, we show that 2 cytokine polymorphisms (IL6$572 \mathrm{G}>\mathrm{C}$ and IL10-592C $>\mathrm{A}$ ) and IL10 serum level 24 hours after $\mathrm{CPB}$ seem to influence the occurrence of adverse outcomes after CABG surgery under CPB.

Death has now become rare after CABG surgery $(1 \%-$ $3 \%$ ), but the rate of postoperative complications still varies between $10 \%$ and $30 \%$. In our study, death occurred in 4 patients $(3.1 \%)$ and CE occurred in 18 patients $(14.3 \%)$, with ARI in $6.4 \%$ and MI in 5.6\%. Our data stand above the median rate of complications reported in a metaanalysis including more than 200,000 patients among 176 series of patients undergoing CABG. ${ }^{16}$ These differences can be explained by the definitions of complications. Actually, ARI after CABG varies from $0 \%$ to $6.2 \%$ and $\mathrm{MI}$ varies from $0 \%$ to $29 \%$. Our definitions of ARI and MI were among the most sensitive in the literature. Cardiac troponin I plasma levels have been shown to be the most relevant markers to assess $\mathrm{MI}$ after revascularization, over electrocardiogram changes and creatine kinase-MB. ${ }^{17}$ In addition, recent cohort studies suffer from the lack of patients displaying a dysmetabolic syndrome, including various metabolic risk factors such as abdominal obesity, dyslipidemia, hypertension, and hyperglycemia, which are thought to be linked to insulin resistance. ${ }^{18}$ These patients are now increasingly referred for $\mathrm{CABG}$ and are prone to develop more postoperative ARIs and MIs. ${ }^{19}$

\section{Cytokines and Clinical Outcomes}

In this study, proinflammatory (IL6 and TNF $\alpha$ ) and antiinflammatory (IL10) plasma levels increased after CPB and decreased 24 hours later, as described in previous studies. ${ }^{20}$ IL6 and TNF $\alpha$ have been shown to be key mediators of
SIRS after CPB. ${ }^{8}$ IL10 is an anti-inflammatory cytokine, which, in contrast, is expected to exert a protective effect on the outcome after $\mathrm{CPB} .^{21}$ However, several studies have suggested that high IL10 plasma levels could also result in an immune "hyporesponsiveness," leading to a higher risk of postoperative infectious complications. ${ }^{5}$ Indeed, we observed more clinical complications in patients with highest IL10 plasma levels 24 hours after CPB.

In 1996 , Rao and colleagues ${ }^{22}$ reported a $9.1 \%$ rate of LCOS after CABG in a large adult population. Our series confirm that LCOS remains one of the major severe complications after surgical coronary revascularization. Although LCOS and MI may be related to periprocedural factors, such as inadequate myocardial protection, a correlation between postoperative IL6 and IL10 plasma levels and postoperative myocardial injury has been noted by Giomarelli and colleagues. ${ }^{23}$ Our data could not confirm this specific finding because LCOS and MIs were not separately analyzed from the other components of our CE. However, it is conceivable that a higher IL10 response reflects the occurrence of a greater inflammatory insult to counteract, which would be consistent with the observation that these high IL10 levels were associated with severe complications.

\section{Single Nucleotide Polymorphisms and Clinical Outcomes}

In this study, we observed an association between clinical complications after $\mathrm{CPB}$ and 2 cytokine gene polymorphisms, SNPs IL6-572G $>\mathrm{C}$ and IL10-592C $>$ A. The SNP IL6-572G $>\mathrm{C}$ has been associated with several cardiovascular disorders, such as coronary heart disease ${ }^{10}$ and abdominal aortic aneurysms. ${ }^{24}$ Furthermore, Jia and colleagues ${ }^{10}$ demonstrated a correlation between this SNP and postoperative MI after cardiac surgery under CPB. Our data suggest that IL6-572G $>\mathrm{C}$ is more generally associated with an adverse postoperative course; patients bearing the IL6572GC and IL6-572CC genotypes have a 9-fold increased risk of experiencing one of the complications included in our CE. In contrast with the study by Brull and colleagues, ${ }^{2}$ a significant association between SNP IL6-572G $>\mathrm{C}$ and IL6 plasma levels was not observed in our study. The study published in 2000 by Terry and colleagues ${ }^{4}$ could explain this discordance. These authors showed a cooperative influence of various genetic polymorphisms on IL6 transcriptional regulation. These polymorphisms were located in the IL6 gene promoter and included SNP IL6-572G $>$ C. In addition, cytokines are most often present in the serum complexed to their soluble receptors. We measured the total production of IL6, because both the free form and that complexed to its receptor are active, whereas in other studies the dosage of IL6 only detected the free form of IL6. ${ }^{25}$ This technical variation in the dosage of IL6 may explain discrepancies in the reported correlation between IL6 serum levels and SNPs for this cytokine. Nevertheless, we did 
observe an association between SNP IL6-572G $>$ C and IL10 plasma levels 24 hours after CPB, and these 2 factors were also, in this study, independently associated with clinical complications.

The SNP IL10-592C $>\mathrm{A}$ is in strong linkage disequilibrium with 2 other SNPs located in the ILIO gene promoter, IL10-1082G $>$ A and $-819 \mathrm{C}>\mathrm{T}$. Haplotype IL10-1082G/$819 \mathrm{C} /-592 \mathrm{C}$ has been associated with higher IL10 plasma levels after pediatric cardiac surgery with $\mathrm{CPB}$, and higher IL10 levels were associated with clinical immunoparalysis, suggesting a higher risk of postoperative infectious complications. ${ }^{5}$ These data are consistent with the association that we observed between the IL10-592CC genotype and a higher risk of clinical complications according to our $\mathrm{CE}$, which included sepsis. No association was found between SNP IL10-592C >A and IL10 plasma levels, but this SNP was associated with clinical complications, as were IL10 plasma levels 24 hours after CPB.

After Bonferroni correction, which is usually required in case of SNP statistical analyses, these 2 associations seemed to be weakened. Nevertheless, our results showed that the association of SNPs IL6-572G $>\mathrm{C}$ and ILIO$592 \mathrm{C}>\mathrm{A}$, along with IL10 plasma level at 24 hours, preexisting COPD or cardiac insufficiency, and age could be predictive of complications after CABG surgery. If confirmed, this predictive model could have implications in the pre- and postoperative management of specific highrisk patients.

\section{Study Limitations}

We acknowledge that this study has some limitations. First, small sample sizes conducted us to correlate the various SNPs with the composite end point, thus making it difficult to assess the specific impact of the genetic pattern on a given postoperative complication. This was unavoidable because the low incidence of individual events required them to be grouped into a composite criterion to provide an adequate statistical power. However, from a merely clinical standpoint, the conclusions remain relevant by showing that the genetic profile allowed the identification of patients at risk of poor bypass-related outcomes, even though the specific component driving the composite end point remains elusive. Second, SIRS may not be always advocated as the cause for some complications of our composite end point. For example, inadequate myocardial protection could lead to postoperative MI or LCOS. However, warm blood cardioplegia (antegrade or retrograde) was consistently used in all patients, which should have contributed to optimize myocardial protection. ${ }^{26}$ Third, this genetic profiling was restricted to a limited number of SNPs. This choice may look oversimplistic in view of the multiplicity of intermingling pathways involved in the genesis of the post-CPB inflammatory response; however, it was dictated by previous published data that identified the selected markers as key players in this response but clearly do not exclude that other SNPs may have a greater predictive value.

\section{CONCLUSIONS}

Overall, our data suggest that focused genetic testing of the IL6-572G $>$ C and IL10-592C $>$ A SNPs might be a tool for identifying patients at the highest risk of poor tolerance to the inflammatory response to CPB and for possibly implementing strategies to mitigate it, such as off-pump surgery, drugs, or device-based interventions. ${ }^{27}$ However, this first requires that the generalization of these genetic diagnostic tests makes them reasonably affordable and thus favorably shifts their cost-to-benefit ratio.

The authors thank Jeanne Meunier for project management and the team of nurses of the Clinical Investgiation Center (APHP, CIC-9201) for technical sampling; and Isabelle Sauret, JeanFrançois Leforestier, and Noël Lucas from the Unité de Recherche Clinique (URC-HEGP) for organization of the project and data management.

\section{References}

1. Warren OJ, Smith AJ, Alexiou C, Rogers PL, Jawad N, Vincent C, et al. The inflammatory response to cardiopulmonary bypass: part 1-mechanisms of pathogenesis. J Cardiothorac Vasc Anesth. 2009;23:223-31.

2. Brull DJ, Montgomery HE, Sanders J, Dhamrait S, Luong L, Rumley A, et al. Interleukin-6 gene $-174 \mathrm{~g}>\mathrm{c}$ and $-572 \mathrm{~g}>\mathrm{c}$ promoter polymorphisms are strong predictors of plasma interleukin-6 levels after coronary artery bypass surgery. $\mathrm{Ar}$ terioscler Thromb Vasc Biol. 2001;21:1458-63.

3. Tomasdottir H, Hjartarson H, Ricksten A, Wasslavik C, Bengtsson A, Ricksten SE. Tumor necrosis factor gene polymorphism is associated with enhanced systemic inflammatory response and increased cardiopulmonary morbidity after cardiac surgery. Anesth Analg. 2003;97:944-9.

4. Terry CF, Loukaci V, Green FR. Cooperative influence of genetic polymorphisms on interleukin 6 transcriptional regulation. J Biol Chem. 2000;275:18138-44.

5. Allen ML, Hoschtitzky JA, Peters MJ, Elliott M, Goldman A, James I, et al. Interleukin-10 and its role in clinical immunoparalysis following pediatric cardiac surgery. Crit Care Med. 2006;34:2658-65.

6. Podgoreanu MV, White WD, Morris RW, Mathew JP, Stafford-Smith M, Welsby IJ, et al. Inflammatory gene polymorphisms and risk of postoperative myocardial infarction after cardiac surgery. Circulation. 2006;114:I275-81.

7. Haicheur N, Escudier B, Dorval T, Negrier S, De Mulder PH, Dupuy JM, et al. Cytokines and soluble cytokine receptor induction after il-12 administration in cancer patients. Clin Exp Immunol. 2000;119:28-37.

8. Murphy GJ, Angelini GD. Side effects of cardiopulmonary bypass: what is the reality? J Card Surg. 2004;19:481-8.

9. Schroeder S, Borger N, Wrigge H, Welz A, Putensen C, Hoeft A, et al. A tumor necrosis factor gene polymorphism influences the inflammatory response after cardiac operation. Ann Thorac Surg. 2003;75:534-7.

10. Jia X, Tian Y, Wang Y, Deng X, Dong Z, Scafa N, Zhang X. Association between the interleukin-6 gene $-572 \mathrm{~g} / \mathrm{c}$ and $-597 \mathrm{~g} / \mathrm{a}$ polymorphisms and coronary heart disease in the han chinese. Med Sci Monit. 2010;16:CR103-8.

11. Chew ST, Newman MF, White WD, Conlon PJ, Saunders AM, Strittmatter WJ, et al. Preliminary report on the association of apolipoprotein e polymorphisms, with postoperative peak serum creatinine concentrations in cardiac surgical patients. Anesthesiology. 2000;93:325-31.

12. Rivera-Chavez FA, Peters-Hybki DL, Barber RC, O'Keefe GE. Interleukin-6 promoter haplotypes and interleukin-6 cytokine responses. Shock. 2003;20: 218-23.

13. Messer G, Spengler U, Jung MC, Honold G, Blomer K, Pape GR, et al. Polymorphic structure of the tumor necrosis factor (tnf) locus: An ncoi polymorphism in the first intron of the human tnf-beta gene correlates with a variant amino acid in position 26 and a reduced level of tnf-beta production. J Exp Med. 1991;173:209-19.

14. Crawley E, Kay R, Sillibourne J, Patel P, Hutchinson I, Woo P. Polymorphic haplotypes of the interleukin-10 5' flanking region determine variable interleukin-10 
transcription and are associated with particular phenotypes of juvenile rheumatoid arthritis. Arthritis Rheum. 1999;42:1101-8.

15. Burzotta F, Iacoviello L, Di Castelnuovo A, Glieca F, Luciani N, Zamparelli R, et al. Relation of the $-174 \mathrm{~g} / \mathrm{c}$ polymorphism of interleukin-6 to interleukin-6 plasma levels and to length of hospitalization after surgical coronary revascularization. Am J Cardiol. 2001;88:1125-8.

16. Nalysnyk L, Fahrbach K, Reynolds MW, Zhao SZ, Ross S. Adverse events in coronary artery bypass graft (CABG) trials: a systematic review and analysis. Heart. 2003;89:767-72.

17. Muehlschlegel JD, Perry TE, Liu KY, Nascimben L, Fox AA, Collard CD, et al. Troponin is superior to electrocardiogram and creatinine kinase $\mathrm{mb}$ for predicting clinically significant myocardial injury after coronary artery bypass grafting. Eur Heart J. 2009;30:1574-83.

18. Reaven GM, Chen YDI. Role of insulin in regulation of lipoprotein metabolism in diabetes. Diabetes Metab Rev. 1988;4:639-52.

19. Baillot RG, Joanisse DR, Stevens LM, Doyle DP, Dionne B, Lellouche F. Recent evolution in demographic and clinical characteristics and in-hospital morbidity in patients undergoing coronary surgery. Can J Surg. 2009;52:394-400.

20. Schmartz D, Tabardel Y, Preiser JC, Barvais L, d'Hollander A, Duchateau J, et al. Does aprotinin influence the inflammatory response to cardiopulmonary bypass in patients? J Thorac Cardiovasc Surg. 2003;125:184-90.
21. Lane JS, Todd KE, Lewis MP, Gloor B, Ashley SW, Reber HA, et al. Interleukin10 reduces the systemic inflammatory response in a murine model of intestinal ischemia/reperfusion. Surgery. 1997;122:288-94.

22. Rao V, Ivanov J, Weisel RD, Ikonomidis JS, Christakis GT, David TE. Predictors of low cardiac output syndrome after coronary artery bypass. J Thorac Cardiovasc Surg. 1996;112:38-51.

23. Giomarelli P, Scolletta S, Borrelli E, Biagioli B. Myocardial and lung injury after cardiopulmonary bypass: role of interleukin (IL)-10. Ann Thorac Surg. 2003;76: 117-23.

24. Smallwood L, Allcock R, van Bockxmeer F, Warrington N, Palmer LJ, Iacopetta B, et al. Polymorphisms of the interleukin-6 gene promoter and abdominal aortic aneurysm. Eur J Vasc Endovasc Surg. 2008;35:31-6.

25. May LT, Viguet H, Kenney JS, Ida N, Allison AC, Sehgal PB. High levels of "complexed" interleukin-6 in human blood. J Biol Chem. 1992;267: 19698-704.

26. Jacob S, Kallikourdis A, Sellke F, Dunning J. Is blood cardioplegia superior to crystalloid cardioplegia? Interact Cardiovasc Thorac Surg. 2008;7:491-8.

27. Yoshizumi K, Ishino K, Ugaki S, Ebishima H, Kotani Y, Kasahara S, et al. Effect of a miniaturized cardiopulmonary bypass system on the inflammatory response and cardiac function in neonatal piglets. Artif Organs. 2009;33: 941-6. 
TABLE E1. Genetic polymorphisms evaluated in the study

\begin{tabular}{|c|c|c|c|c|c|c|}
\hline Gene (symbol) & $\begin{array}{c}\text { Nucleotide } \\
\text { substitution }\end{array}$ & $\begin{array}{l}\text { Genomic } \\
\text { context }\end{array}$ & $\begin{array}{c}\text { SNP } \\
\text { identification* }\end{array}$ & $\begin{array}{c}\text { Cytogenetic } \\
\text { locus }\end{array}$ & $\begin{array}{c}\text { Minor allele } \\
\text { frequency }\end{array}$ & $\begin{array}{c}\text { Hardy-Weinberg } \\
P \\
\end{array}$ \\
\hline \multirow[t]{3}{*}{ Interleukin 6 (ILO) } & $-597 \mathrm{G}>\mathrm{A}$ & $5^{\prime} \mathrm{UTR}$ & rs 1800797 & $7 \mathrm{p} 15.3$ & 0.306 & .246 \\
\hline & $-572 \mathrm{G}>\mathrm{C}$ & $5^{\prime} \mathrm{UTR}$ & rs 1800796 & & 0.079 & .141 \\
\hline & $-174 \mathrm{G}>\mathrm{C}$ & $5^{\prime} \mathrm{UTR}$ & rs1800795 & & 0.310 & .655 \\
\hline \multirow[t]{2}{*}{ Interleukin 10 (IL10) } & $-592 \mathrm{C}>\mathrm{A}$ & $5^{\prime} \mathrm{UTR}$ & rs 1800872 & $1 \mathrm{p} 32.1$ & 0.262 & .532 \\
\hline & $* 117 \mathrm{C}>\mathrm{T}$ & $3^{\prime} \mathrm{UTR}$ & rs3024496 & & 0.437 & .467 \\
\hline $\begin{array}{l}\text { Tumor necrosis } \\
\text { factor- } \alpha(T N F \alpha)\end{array}$ & $-308 \mathrm{G}>\mathrm{A}$ & $5^{\prime} \mathrm{UTR}$ & rs1800629 & $6 \mathrm{p} 21.33$ & 0.135 & .823 \\
\hline \multirow[t]{2}{*}{ Lymphotoxin alpha (LTA) } & $+252 \mathrm{~A}>\mathrm{G} \dagger$ & intron 1 & rs 909253 & $6 \mathrm{p} 21.33$ & 0.333 & .423 \\
\hline & $37 \mathrm{~T}>\mathrm{C}$ & Cys13Arg & rs2229094 & & 0.254 & .596 \\
\hline \multirow[t]{2}{*}{ Apolipoprotein E (APOE) } & $388 \mathrm{~T}>\mathrm{C}$ & Cys130Arg & rs429358 & $19 q 13.32$ & $\mathrm{e} 2: 0.044$ & .433 \\
\hline & $526 \mathrm{C}>\mathrm{T}$ & Arg176Cys & rs7412 & & e4: 0.115 & \\
\hline
\end{tabular}

UTR, Untranslated region. *From the National Center for Biotechnology Information's dbDNP public database (http://www.ncbi.nlm.nih.gov/SNP/). †Notation most used in association studies. The HGVS nomenclature is c. $-10+90 \mathrm{~A}>\mathrm{G}$.

TABLE E2. Primers used for genotype analysis

\begin{tabular}{|c|c|c|c|}
\hline Primer & Sequence $5^{\prime} \rightarrow \mathbf{3}^{\prime}$ & Amplicon length (bp) & Annealing T ( C) \\
\hline IL6-F & TGGCAAAAAGGAGTCACACA & 659 & 64 \\
\hline IL6-R & GCCTCAGACATCTCCAGTCC & & \\
\hline IL6-Fint & CAAGACATGCCAAAGTGCTG & & \\
\hline IL6-Rint & GAGTTTCCTCTGACTCCATCG & & \\
\hline IL10-592-F & CTGTGCCTCAGTTTG CTCAC & 487 & 61 \\
\hline IL10-592-R & CCTCAGCTGTGGGTTCTCAT & & \\
\hline IL10*117-F & GGAGAACAAGCAACCTCTGC & 592 & 61 \\
\hline IL10*117-R & AGCTAG AAAGCGTGGTCAGG & & \\
\hline LTACys13Arg-F & TGTCTCCCTCTGCTCACCTT & 338 & 67 \\
\hline LTACys13Arg-R & GGCTCTAGGGCTCAAGGTTT & & \\
\hline APOE-F & TGAAGGAGTTGAAGGCCTAC & 502 & 58 \\
\hline APOE-R & TGCTCCTTCACCTCGTCCAG & & \\
\hline TNF-F & AGGCAATAGGTTTTGAGGGCCAT & 107 & 60 \\
\hline TNF-R & TCCTCCCTGC TCCGATTCCG & & \\
\hline $\mathrm{LTA}+252-\mathrm{F}$ & CCGTGCTTCGTGCTTTGGACTA & 782 & 54 \\
\hline $\mathrm{LTA}+252-\mathrm{R}$ & AGAGGGGTGGATGCTTGGGTTC & & \\
\hline
\end{tabular}

$b p$, Base pair; $T$, temperature; $F$, forward; $R$, reverse; int, internal sequencing primer. 
TABLE E3. Cytokine plasma levels and polymorphism associations Cytokine levels and polymorphism associations (at each cytokine measurement)

\begin{tabular}{|c|c|c|c|c|c|c|c|}
\hline \multirow{2}{*}{$\frac{\text { Cytokine measure }}{(\mathrm{TNF} \alpha) \text { before } \mathrm{CPB}}$} & \multirow{2}{*}{$\frac{\text { SNP }}{\text { LTA Cys13Arg }}$} & \multicolumn{3}{|c|}{ Median (Q1-Q3) per genotype } & \multirow{2}{*}{$\begin{array}{c}\text { Univariate } \\
\boldsymbol{P} \\
.097\end{array}$} & \multicolumn{2}{|r|}{$\begin{array}{c}\text { Multivariable } \\
P\end{array}$} \\
\hline & & CysCys & CysArg & ArgArg & & & NS \\
\hline & & $1.0(0.0-2.0)$ & $1.0(0.0-2.0)$ & $2.0(1.0-4.0)$ & & & \\
\hline & $T N F-308 \mathrm{G}>\mathrm{A}$ & GG & GA & $\mathrm{AA}$ & .073 & & .039 \\
\hline & & $1.0(1.0-2.0)$ & $1.0(0.0-1.0)$ & $0.5(0.0-1.0)$ & & & \\
\hline \multirow[t]{4}{*}{ (IL6) $4 \mathrm{~h}$ after CPB } & IL6-174G $>\mathrm{C}$ & GG & $\mathrm{GC}$ & $\mathrm{CC}$ & .056 & & NS \\
\hline & & $91(68-159)$ & $106(73-165)$ & $63(48-105)$ & & & \\
\hline & $T N F-308 \mathrm{G}>\mathrm{A}$ & GG & GA & AA & .099 & & NS \\
\hline & & $93(68-145)$ & $139(73-171)$ & $169(155 ; 183)$ & & & \\
\hline \multirow[t]{6}{*}{ (IL6) $24 \mathrm{~h}$ after CPB } & IL6-597G $>\mathrm{A}$ & GG & GA & AA & .054 & & NS \\
\hline & & $58.5(41.5-81)$ & $67(51-115)$ & $49.5(37-63)$ & & & \\
\hline & IL6-174G $>\mathrm{C}$ & GG & GC & $\mathrm{CC}$ & .059 & & NS \\
\hline & & $58(42-81)$ & $68(50-114)$ & $53(43-62)$ & & & \\
\hline & $A P O E$ alleles 3 & 0 & 1 & 2 & .011 & & .027 \\
\hline & & $46(38-53)$ & $91(53-121)$ & $59(38-74)$ & & & \\
\hline \multirow[t]{2}{*}{ (IL10) $24 \mathrm{~h}$ after CPB } & IL6 $-572 \mathrm{G}>\mathrm{C}$ & GG & GC & $\mathrm{CC}$ & .040 & & NS \\
\hline & & $2(0-10)$ & $7(2-16)$ & $78(34-122)$ & & & \\
\hline \multirow[t]{3}{*}{$(\mathrm{TNF} \alpha) 24 \mathrm{~h}$ after $\mathrm{CPB}$} & LTA Cys13Arg & CysCys & CysArg & ArgArg & .088 & & NS \\
\hline & & $1.0(0.0-3.0)$ & $2.0(1.0-2.0)$ & $3.0(2.0-4.0)$ & & & \\
\hline & & \multicolumn{6}{|c|}{ Cytokine kinetic and polymorphism associations } \\
\hline & & \multicolumn{3}{|c|}{ (IL6) $($ mean \pm SD $)$} & & & \\
\hline SNP & Genotype & Before CPB & $4 \mathrm{~h}$ after CPB & $24 \mathrm{~h}$ after CPB & & $P_{1}$ & $P_{2}$ \\
\hline \multirow[t]{4}{*}{$A P O E$ alleles 3} & 0 & $3.0 \pm 2.8$ & $52.0 \pm 15.6$ & $45.5 \pm 10.6$ & & .048 & NS \\
\hline & 1 & $3.8 \pm 9.7$ & $122.2 \pm 61.0$ & $99.2 \pm 68.5$ & & & \\
\hline & 2 & $4.6 \pm 23.8$ & $131.5 \pm 160.5$ & $64.9 \pm 39.6$ & & & \\
\hline & & \multicolumn{3}{|c|}{$(\mathrm{TNF} \alpha)($ mean $\pm \mathrm{SD})$} & & & \\
\hline SNP & Genotype & before CPB & $4 \mathrm{~h}$ after CPB & $24 \mathrm{~h}$ after CPB & & $P_{1}$ & $P_{2}$ \\
\hline \multirow[t]{3}{*}{$T N F-308 \mathrm{G}>\mathrm{A}$} & GG & $1.7 \pm 2.6$ & $4.4 \pm 4.0$ & $2.1 \pm 3.3$ & & .056 & NS \\
\hline & GA & $1.0 \pm 1.3$ & $4.3 \pm 4.7$ & $2,6 \pm 6.7$ & & & \\
\hline & AA & $0.5 \pm 0.7$ & $5.0 \pm 1.4$ & $1.0 \pm 1.4$ & & & \\
\hline \multirow[t]{3}{*}{ LTA Cys13Arg } & CysCys & $1.2 \pm 1.2$ & $4.4 \pm 4.1$ & $2.2 \pm 4.6$ & & .019 & NS \\
\hline & CysArg & $1.7 \pm 3.4$ & $4.4 \pm 4.3$ & $2.1 \pm 4.1$ & & & \\
\hline & ArgArg & $3.0 \pm 2.9$ & $4.3 \pm 3.5$ & $3.4 \pm 2.6$ & & & \\
\hline
\end{tabular}

$N S$, Not significant; $P_{l}$, genotype effect; $P_{2}$, genotype $\times$ kinetics interaction; $S D$, standard deviation. Concentration unit is $\mathrm{pg} / \mathrm{mL}$. 